\title{
The Doctor Will See Yourself Now: Review and Discussion of a Mass-market Self-service Technology for Medical Advice
}

\author{
Joseph Ollier ${ }^{1} \mathbb{C}^{\mathrm{a}}$ and Tobias Kowatsch ${ }^{2,3} \mathbb{B}^{\mathrm{b}}$ \\ ${ }^{I}$ Center for Digital Health Interventions, Chair of Technology Marketing, ETH Zurich, Zurich, Switzerland \\ ${ }^{2}$ Center for Digital Health Interventions, Chair of Information Management, ETH Zurich, Zurich, Switzerland \\ ${ }^{3}$ Center for Digital Health Interventions, Institute of Technology Management, St. Gallen, Switzerland \\ jollier@eth.ch,tobias.kowatsch@unisg.ch
}

Keywords: Self-service Technology, Digital Health, Data Privacy.

Abstract: Leveraging new technological tools in medical service delivery has been shown as important factor adding scalability and/or value to patient care. However, as of yet, relatively little research has focused on the implementation of mass-market digital health products to address population needs. The current paper examines one such tool; a browser-optimized smartphone app developed by a major Swiss health insurance, offering validated medical information for patients to identify the optimal care path of action (i.e. self-care, pharmacy visit, general practitioner visit, hospital visit). Summary statistics of usage data from 149922 users over 6 months are outlined, overviewing; (i) key usage cases for the service over time, (ii) for whom the app was used, (iii) dropout rates and potential design pitfalls. Possible themes are identified such as the importance of additional information regarding privacy or service/usage experience information, and some considerations for both the research, design and implementation communities.

\section{INTRODUCTION}

Never before in human history has so much information been available at a few taps of the finger (Acquisti, Brandimarte, \& Loewenstein, 2015), yet finding trustworthy and legitimate sources of medical information remains a challenge (Soldaini \& Goharian, 2017). At one end of the spectrum, digital platforms have enabled the recycling of long disputed information to new audiences, for example, the rise of "anti-vaxxer" campaigns (Kennedy, 2019), whereas at the other end of the spectrum, digital artefacts have enabled health information to connect with new audiences in a meaningful and engaging manner (Barello et al., 2015). Somewhere between these two extremes resides the average individual, searching for information online and making health decisions for themselves or their family. With over 1 billion health related searches globally on Google, equating to 70 000 queries a minute, the consumer desire for health information is clear (M. Murphy, 2019).

For policy makers and firms alike, addressing this desire for health information is both an opportunity and a challenge. Opportunities lie in reducing the burden for healthcare systems; for example within Switzerland, despite rising hospital admissions, only $2.4 \%$ of the national healthcare budget (equating to 19 CHF per month) is spent on preventative measures such as the dissemination of healthcare information (FSO, 2019). For firms, creating trustworthy health services through self-service technologies can address this state of consumer confusion; forging a meaningful connection with patients/customers and delivering medical services that add value (Sweeney, Danaher, \& McColl-Kennedy, 2015; W.-T. Wang, Cheng, \& Huang, 2013). For all parties, addressing these needs solves the long-standing issue of individuals entering the health system at the wrong point in time (Mayer, Villaire, \& Connell, 2005); either too early (before adequate self-care steps have been taken) or too late (when the danger of serious complications has increased).

In seeking to address these challenges a number of mass-market digital tools have been developed by organizations, offering information on medical symptoms, check-ups, diagnosis or other information (Lupton, 2016), such as Ada, a digital app health companion (Ada, 2020) or the Health A-Z website

a (iD) https://orcid.org/0000-0001-8603-0793

b(iD https://orcid.org/0000-0001-5939-4145 
(NHS, 2020). However, as of yet, consumer reception to such medical self-service technologies is relatively little understood due to a lack of usage data released by the implementers of such services to the general public. The current paper therefore overviews some first insights based on six months usage data with one such tool developed and offered starting 2018 by a major health insurer in Switzerland.

The remainder of this paper is structured as follows: first, we review the conceptual background of digital health information tools, including the justification for both policy makers and firms that enact them. Next, we overview the self-service technology in use (a smartphone-optimized browser app), and then we examine the highlighted results from available usage data. Finally, findings are reviewed in light of relevant academic work and useful future research streams are addressed.

\section{CONCEPTUAL BACKGROUND}

In making health choices, it has long been known that individuals face difficulties in making suitable decisions within a complex healthcare system (PaascheOrlow, Parker, Gazmararian, Nielsen-Bohlman, \& Rudd, 2005). Individuals require easily available, accurate and timely information (Hibbard \& Peters, 2003), however the abundance of information does not always translate into more informed choices. Visits to the emergency department for minor complaints (Mayer et al., 2005; S. M. Murphy \& Neven, 2014; Rieffe, Oosterveld, Wijkel, \& Wiefferink, 1999) or unnecessary general practitioner visits when a pharmacy could provide better self-care information and medication (Hassell, Rogers, \& Noyce, 2000) have long been established as contributing to increased healthcare system costs (Hewner, Sullivan, \& Yu, 2018; Mayer et al., 2005; Rieffe et al., 1999).

Free healthcare services providing health information have been touted as potentially useful solutions, preventing individuals entering the healthcare system at the wrong entry point (Hwang, Liao, Griffin, \& Foley, 2012). This has included phone consultations (Hallfors, Saku, Makinen, \& Madanat, 2018), and more recently the utilization of digital platforms (Bahadori, Teymourzadeh, \& Mousavi, 2018) such as email and smartphone communications (Chua et al., 2017). These free services have the added benefit of being a potentially useful way to reach non-insured and/or low income groups which may benefit in particular with a trusted health information source (Hwang et al., 2012).

For patients, use of digital tools have been shown to lead to higher health literacy (Xie, 2011) and by consequence, less unnecessary emergency room or general practitioner visits, which contribute to reducing overcrowding in healthcare systems (FSO, 2019). From a business perspective, for private enterprises creating digital tools, services research has shown the ability to work well with healthcare resources enables a "co-creation" of value, with positive downstream consequences for both customer and firm (McCollKennedy, Vargo, Dagger, Sweeney, \& van Kasteren, 2012; Sweeney et al., 2015). However, to date, relatively little commercial data has been available examining consumer reception to the introduction to such digital products at a mass-market / population level. Yet this is vital, for policy makers, practitioners and academics to push the development of such digital tools to their next steps of development.

\section{METHOD}

The current paper outlines data from a browser-based smartphone app created by a major Swiss health insurance firm, available on any device without requiring the app's download. The app was developed based on a verified medical framework created independently by doctors and adapted by the insurance firm into a dialogue/survey like format. Individuals could input their main and secondary complaints and answer a variety of questions to receive medical advice. The medical advice consisted of a recommendation of a course of action, rather than a medical diagnosis per se, as the apps purpose was to direct individuals to the correct healthcare system entry point for further evaluation. Upon completion of the dialogue, individuals would be recommended to; (i) take self-care steps, (ii) visit a pharmacy, (iii) visit their general practitioner, (iv) visit emergency department, for example. See figures 1-4 for screenshots of the tool in English.

In total, 149222 app uses were recorded during 6 months of field use in German-speaking Switzerland, from the product launch in September 2018 to the end of the data collection period in February 2019. The tool was not widely marketed or available to the general public, but current customers of the health insurance firm were emailed a link stating that the product was live and that they could access and use the tool. A selection of data was made available by our partner company for the purposes of disseminating knowledge of healthcare innovations in the field. Data made available includes; (i) for whom the tool was used (age and gender), (ii) the primary symptom (main usage reason), (iii) changes 


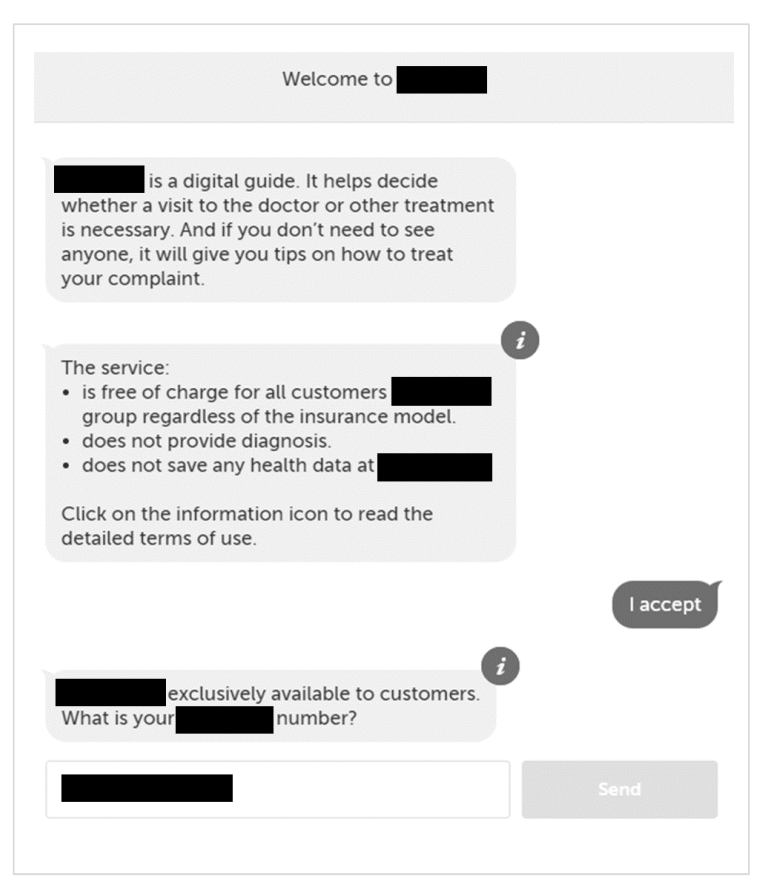

Figure 1: Dialogue start.

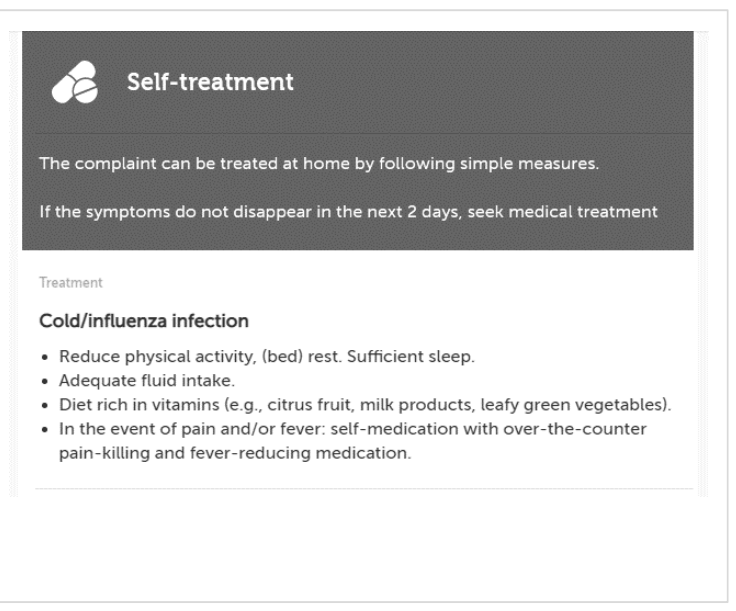

Figure 3: Self-care recommendation.

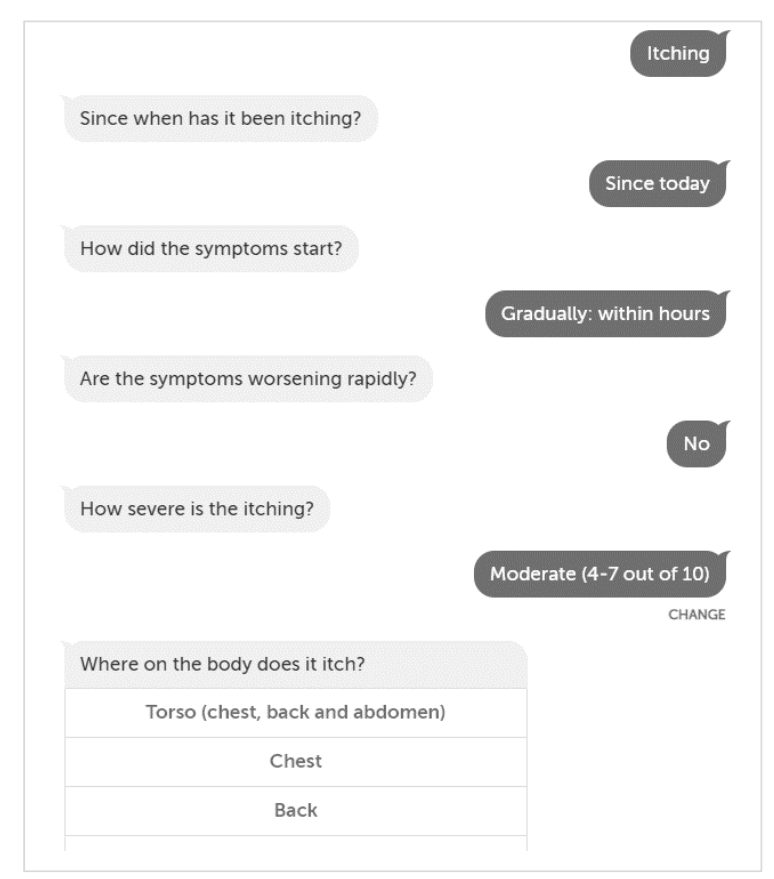

Figure 2: Dialogue symptom selection.

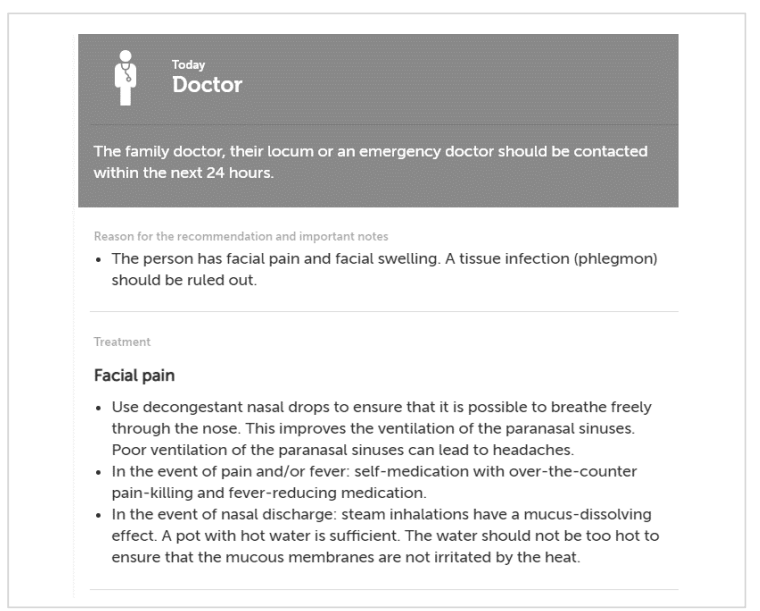

Figure 4: Doctor-visit recommendation.

Table 1: Buttons leading out of optimal usage path.

Use

Terms and conditions as PDF Info Icons

Emergency

Frequently asked questions

Contact center
Button

Further information about the app, service information and data and security

Contact numbers for call center staff 
in disease ranking, showing most common symptoms selected between 1-3 (first three months) and 4-6 months (latter three months) respectively, (iv) users continuing/drop outs (per section of the app, where section consists of a completed dialogue section around symptoms and/or a separate page of information) and buttons leading out of the optimal usage path (i.e. clicking to view FAQs, or further information buttons etc.) as summarized in table 1 .

\section{RESULTS}

Figure 5 shows a breakdown of the use cases by age and gender, whereby these figures reflect the intended recipient of the medical information. Overall cases were recorded for all age groups, however, individuals aged $15+$ reflect the bulk of intended recipients of information. This is potentially as users still exhibit a lack of trust and/or preference for human support for cases of the very young or elderly.
Figure 6 outlines primary symptoms selected by users. As likely to be expected, the primary use case for the app is for common acute illnesses. "Other complaints" (not included in figure) include conditions such as insect stings/bites, heart palpitations, joint problems etc. which occur less frequently but require more specialist knowledge.

Table 2 further elucidates symptom choices by showing the ranking of main symptom selected in November 2018, in the first 3 months, as well as in February 2019, in the latter 3 months. Rank 1 indicates the most selected symptom, with descending scores equating to decreased frequency of selection. Symptom changes over time outlined in the table indicate that there could be some seasonality in symptom prevalence; for example, with vomit/nausea and fever changing dramatically in ranking. This could also point to the usefulness of digital tools in predicting population level healthcare trends, for example, the spread of illnesses as outlined in the discussion later.

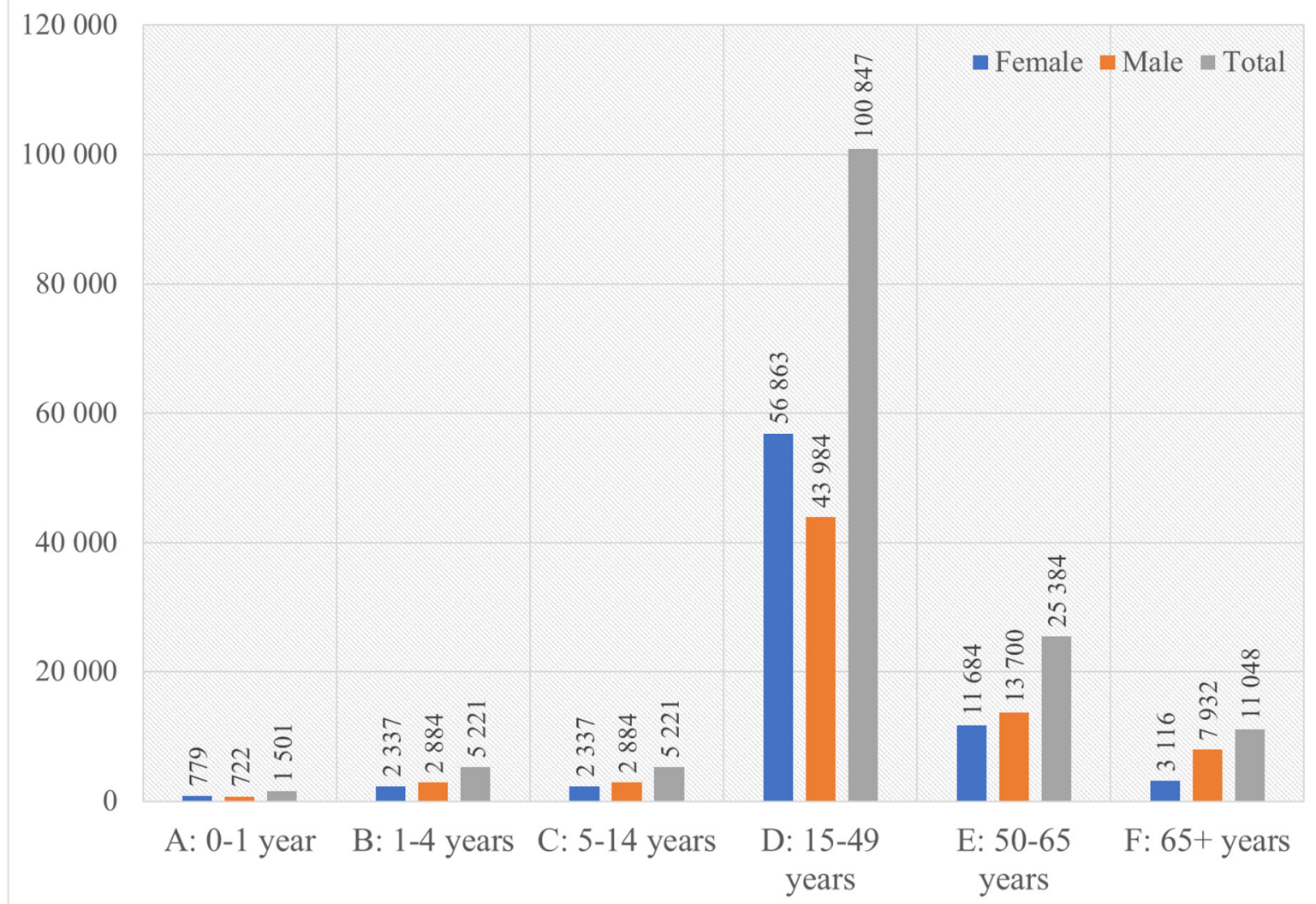

Figure 5: For whom the tool was used (by age and gender, total $\mathrm{N}=149$ 222). 


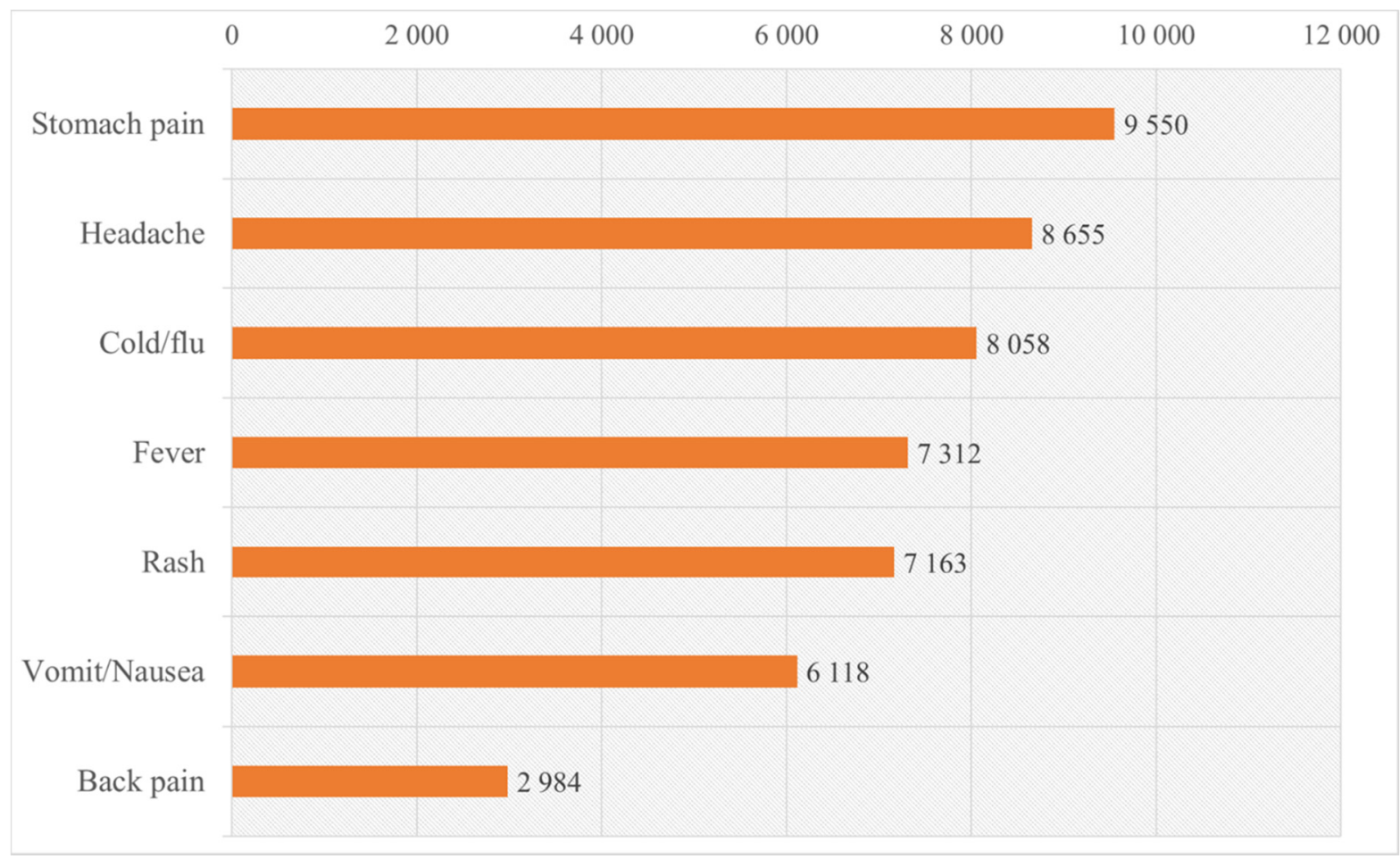

Figure 6: Primary symptoms selected (total N=149 222, other symptoms N=99 382).

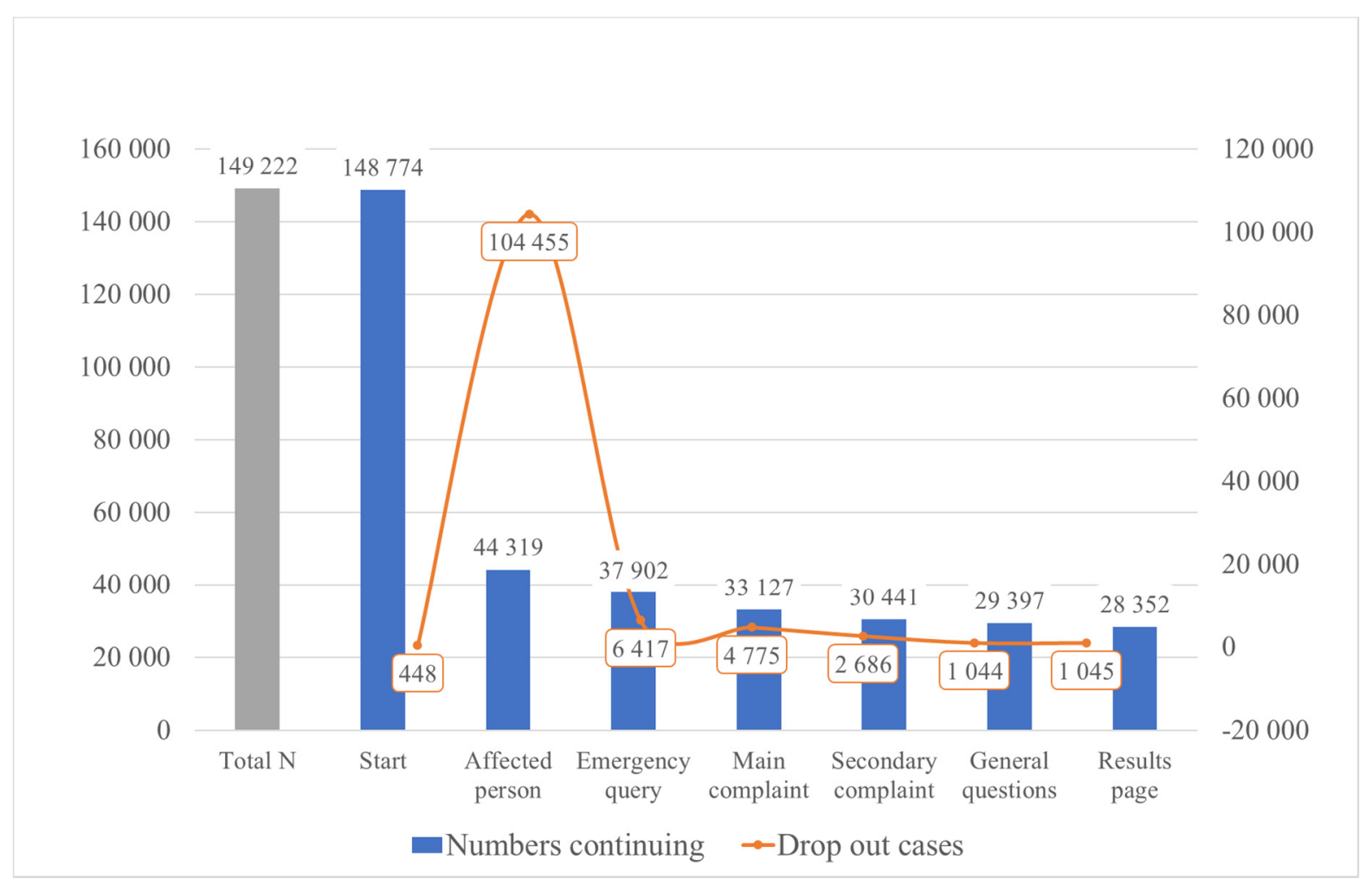

Figure 7: App dialogue section / page visited. 
Table 2: Symptom ranking for 3 months usage (1 is highest rank).

\begin{tabular}{cccc} 
Symptom & $\begin{array}{c}\text { Ranking between Sept 2018 to } \\
\text { Nov 2018 }\end{array}$ & $\begin{array}{c}\text { Ranking between Dec 2018 to } \\
\text { Feb 2019 }\end{array}$ & $\begin{array}{c}\text { Ranking } \\
\text { change }\end{array}$ \\
\hline Stomach pain & 1 & 1 & 0 \\
Headache & 3 & 2 & +1 \\
Cold/flu & 6 & 3 & +3 \\
Fever & 14 & 4 & +10 \\
Rash & 2 & 5 & -3 \\
Vomit/Nausea & 18 & 6 & +12 \\
Back pain & 5 & 12 & -7 \\
\hline
\end{tabular}

Terms and Conditions as PDF

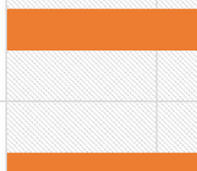

Information Icons

1492

Frequently Asked Questions

Emergency Help 0

Contact Center

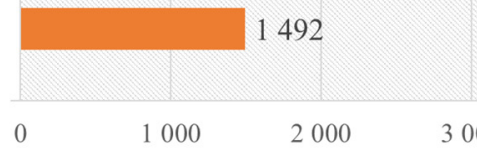

1343

Figure 8: Buttons out of the optimal usage path.

Figure 7 shows the number of remaining users/dropouts through each page/section of the app. As can be evidenced, once users have begun the main dialogue (i.e. talking about the affected person), the majority continue through to the results page. However, a large number of individuals drop out between the start page and the affected person page. This is possibly due to the request of the customer insurance number, and subsequent fears around data privacy, as explored further in the discussion.

Figure 8 outlines buttons clicked upon by the user, removing them from the "optimal" usage path (i.e. the most direct path to results, buttons that mayrequire navigating back to main usage path). Buttons clicked include; requiring terms and conditions as a PDF, information icons (explaining medical symptoms/jargon), frequently asked questions, and contact center (i.e. how to contact a human for help). Interestingly, there were no uses of the emergency contact button; perhaps as individuals feared requesting an ambulance by using the button, or perhaps as users would prefer to use more traditional channels in case of emergency. As also overviewed in the discussion, these results hint at the importance of including sufficient information within the main app usage path, so as to not derail customers from the intended usage/service experience. 


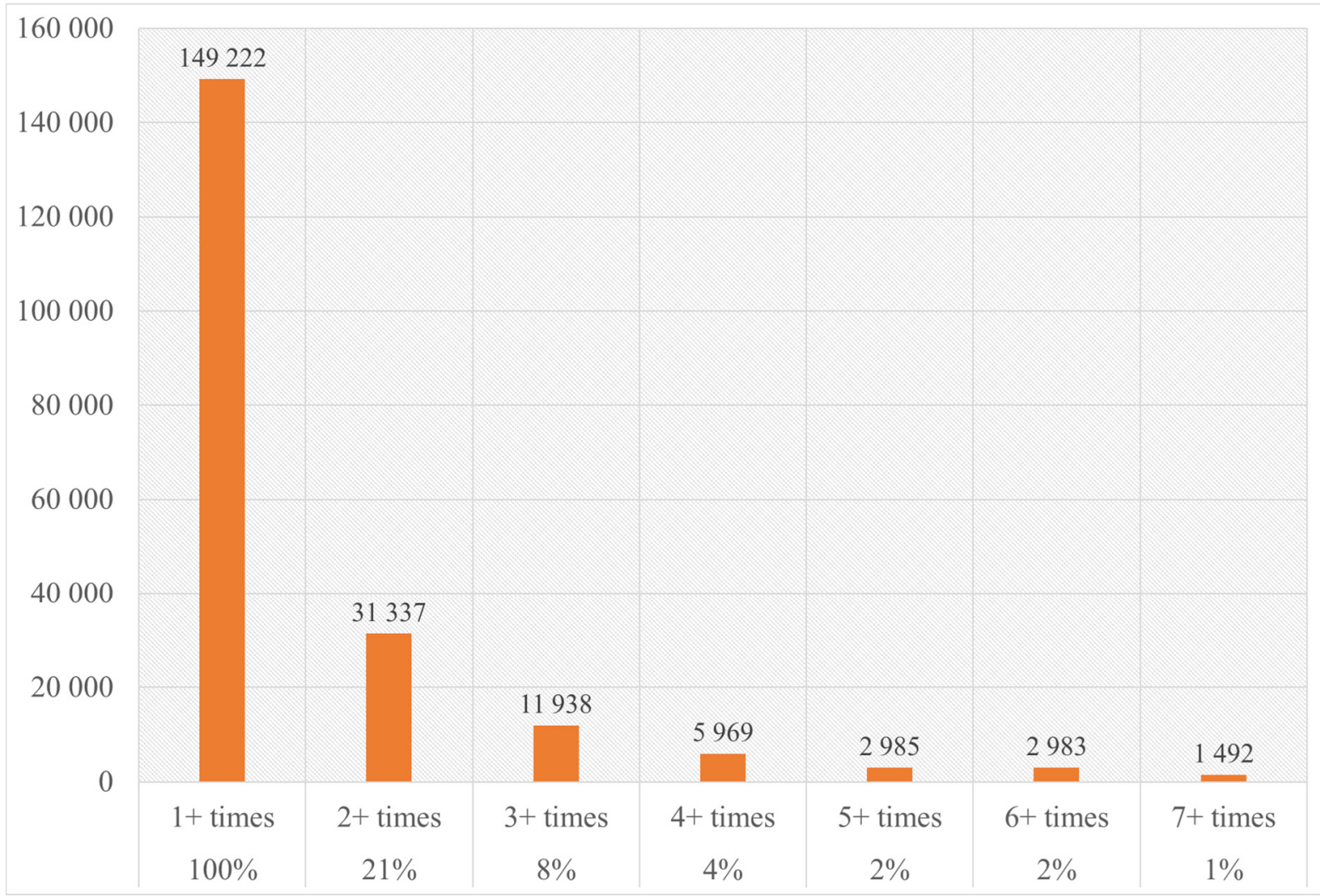

Figure 9: Buttons out of the optimal usage path

Finally figure 9 highlights the number of users returning to use the medical tool again, with the majority of users using the app only once. Figures show that some individuals did return to use the app again over the six-month period; $21 \%$ of users $(n=31337)$ used the app two or more times, $8 \%$ three or more times ( $\mathrm{n}=11938)$ and so on.

\section{DISCUSSION AND FUTURE RESEARCH}

Trust in novel digital medical platforms and medical services has been identified as of importance previously (Mackert, Mabry-Flynn, Champlin, Donovan, \& Pounders, 2016; Moreira \& Silva, 2015), and for digital platforms more generally, trusting preferences have been linked to both consumer and platform characteristics (Komiak \& Benbasat, 2006; Metzger, 2006, 2007; W. Q. Wang \& Benbasat, 2007). Usage statistics indicate that the app was primarily used for older teenagers and adults, with relatively fewer cases for more at-risk groups (i.e. the young and elderly) where consequences of misdiagnosis are more severe. In addition, primary symptoms selected in the app were for common complaints which typically consumers already have an adequate level of health knowledge about (i.e. cold, fever, rash). Thusly it appears that although consumers welcome using these apps, they still exhibit a degree of caution and mistrust about relying on them for more serious medical queries, as also further evidenced by no use of the emergency button within the app. It would therefore be interesting to examine how consumers react to using such digital platforms, when the intended medical enquiry is more severe, and something for future researchers to investigate.

The number of app dialogue sections/pages visited and the dropout rate is also interesting considering heightened privacy concerns amongst the general populace after recent well publicized scandals (Isaak \& Hanna, 2018; Zhang et al., 2018). Despite attracting a large number of customers to the app launch site, many dropped out when asked to provide their customer insurance number and date of birth for validation purposes, even though they were informed no health data would be saved by the firm. Previous research has identified the timing of consent is of importance in disclosure decisions (Anderson \& 
Agarwal, 2011), and one explanation therefore may be that individuals were not significantly engaged with the service offering before being asked to provide information and thusly many left the app. Alternatively, as user "emotions and resistances" may stand in the way of successful digital health tools (Lupton, 2013), it may be that individuals simply did not believe the company when they stated no health data would be saved yet also asked health insurance customer number. As privacy disclosures are both a legal requirement, and evidently of importance for users, future research may wish to consider alternative methods of framing privacy related information which connects with individuals on a meaningful level (Zhang et al., 2018).

In addition to privacy related information, further service/usage experience information may also be of benefit, as evidenced from the utilization of buttons out of the main interaction path. Users selected to receive further information related to privacy (e.g. terms and conditions) or service matters (e.g. frequently asked questions) indicating that service roles were unclear (Solomon, Surprenant, Czepiel, \& Gutman, 1985). Expectation setting has been known as importance in service evaluations (Ofir \& Simonson, 2007), and including extra information within the main section of the app (particularly if it is a dialogue based format as the current service) may serve to "onboard" individuals to the service experience (Rawson, Duncan, \& Jones, 2013). This has been found as particularly important in extant research where service literacy is important (Voorhees et al., 2017), which is likely the case with novel digital products such as those employed in healthcare.

The potential of use of such apps for health care providers is also outlined when examining symptom changes from 3 months and 6 months which show changes in the ranking of symptoms, for example, fever changing from ranked $14^{\text {th }}$ to $4^{\text {th }}$. Previously tracking symptom web searches and social media posts has been used to predict influenza spread at both population and sub-population levels (Santos \& Matos, 2014; Volkova, Ayton, Porterfield, \& Corley, 2017). Thusly one could suppose that providing the provision of these new tools was widespread enough, and relevant permissions were given to healthcare bodies to access the data, they may provide a highly accurate data source for making predictions. This may resolve some of the issues around inaccurate information used for predictions, for example with Google Flu (Kandula \& Shaman, 2019). Future research should also consider how such tools can be monitored in terms of whether they successfully prevent unnecessary emergency room or general practitioner visits (Bahadori et al., 2018), or successfully refer individuals to the correct healthcare entry point.

Finally, repeat usage numbers show that there exists some interest amongst the populace in exploring digital healthcare tools. The current selfservice technology utilized a dialogue-type interaction, guiding individuals through a linear path to their results, in a dyadic manager mimicking regular clinician-patient communication (McCollKennedy et al., 2012; Sweeney et al., 2015). Virtual agents such as text-based chatbots have been widely applied to medical contexts to act as digital coaches (Kowatsch et al., 2017), for example, the cognitivebehavioral therapy chatbot "WoeBot" (Fitzpatrick, Darcy, \& Vierhile, 2017). It would be interesting to discern whether making such self-services more anthropomorphized would bring any benefits in terms of repeat usage and minimizing drop outs in future research, as anthropomorphism has been touted as a key satisfaction driving mechanism for "service robots" placed in the frontline (Wirtz et al., 2018).

For future practitioners seeking to implement such digital tools, the authors would firstly note that the number of total uses indicates a good appetite amongst consumers to try such tools. Important however, as noted earlier in the discussion, is to find ways to successfully onboard users to the service experience through use of supplementary information. In particular, privacy concerns seem to dominate, and a key recommendation for practitioners wishing to roll out such digital selfservice technologies is to find ways to reduce user privacy concern. This could be through the use of additional privacy assurance disclosures, for example, or not requesting customer details (e.g. login information) immediately upon starting the interaction.

\section{SUMMARY AND NEXT STEPS}

In summary results show that such digital self-service technologies hold great potential with large numbers of customers visiting the app site within a relatively short time frame. However, the results also show that trust in such digital services is not entirely established yet, as evidenced by the large number of drop outs after requesting the potentially sensitive customer insurance number. In addition, the use cases for the product seem to be for relatively benign complaints, rarely for at-risk groups (young, elderly) and never in the case of emergency. Future research should 
examine how information relating to privacy and service/usage experience can be made more meaningful and/or clear to users, and whether this is evidenced in changing use cases and usage patterns.

\section{REFERENCES}

Acquisti, A., Brandimarte, L., \& Loewenstein, G. (2015). Privacy and human behavior in the age of information. Science, 347(6221), 509-514. doi:10.1126/science. aaa 1465

Ada. (2020). Ada: Your Digital Health Companion. Retrieved from https://ada.com/

Anderson, C. L., \& Agarwal, R. (2011). The Digitization of Healthcare: Boundary Risks, Emotion, and Consumer Willingness to Disclose Personal Health Information. Information Systems Research, 22(3), 469-490. doi:10.1287/isre.1100.0335

Bahadori, M., Teymourzadeh, E., \& Mousavi, S. M. (2018). eHealth solutions and nonurgent visits in emergency departments. Technol Health Care, 26(3), 571-572. doi: $10.3233 /$ THC-181290

Barello, S., Triberti, S., Graffigna, G., Libreri, C., Serino, S., Hibbard, J., \& Riva, G. (2015). eHealth for Patient Engagement: A Systematic Review. Front Psychol, 6, 2013. doi:10.3389/fpsyg.2015.02013

Chua, M. E., Saunders, M. A., Bowlin, P. R., Ming, J. M., Lopes, R. I., Farhat, W. A., \& Dos Santos, J. (2017). Impact of smartphone digital photography, email, and media communication on emergency room visits posthypospadias repair. Can Urol Assoc J, 11(3-4), E134E137. doi:10.5489/cuaj.4170

Fitzpatrick, K. K., Darcy, A., \& Vierhile, M. (2017). Delivering Cognitive Behavior Therapy to Young Adults With Symptoms of Depression and Anxiety Using a Fully Automated Conversational Agent (Woebot): A Randomized Controlled Trial. JMIR Ment Health, 4(2), e19. doi:10.2196/mental.7785

FSO. (2019). Health Pocket Statistics 2018. Switzerland: Federal Statistics Office Retrieved from https://www.bfs.admin.ch/bfs/en/home/statistics/health /health-system.assetdetail.7347549.html

Hallfors, E., Saku, S. A., Makinen, T. J., \& Madanat, R. (2018). A Consultation Phone Service for Patients With Total Joint Arthroplasty May Reduce Unnecessary Emergency Department Visits. J Arthroplasty, 33(3), 650-654. doi:10.1016/j.arth.2017.10.040

Hassell, K., Rogers, A., \& Noyce, P. (2000). Community pharmacy as a primary health and self-care resource: a framework for understanding pharmacy utilization. Health Soc Care Community, 8(1), 40-49. doi:10.1046/j.1365-2524.2000.00222.x

Hewner, S., Sullivan, S. S., \& Yu, G. (2018). Reducing Emergency Room Visits and In-Hospitalizations by Implementing Best Practice for Transitional Care Using Innovative Technology and Big Data. Worldviews Evid Based Nurs, 15(3), 170-177. doi:10.1111/wvn.12286
Hibbard, J. H., \& Peters, E. (2003). Supporting informed consumer health care decisions: data presentation approaches that facilitate the use of information in choice. Annu Rev Public Health, 24, 413-433. doi:10.1146/annurev.publhealth.24.100901.141005

Hwang, W., Liao, K., Griffin, L., \& Foley, K. L. (2012). Do free clinics reduce unnecessary emergency department visits? The Virginian experience. J Health Care Poor Underserved, 23(3), 1189-1204. doi:10.1353/hpu. 2012.0121

Isaak, J., \& Hanna, M. J. (2018). User Data Privacy: Facebook, Cambridge Analytica, and Privacy Protection. Computer, 51(8), 56-59. doi:10.1109/mc. 2018.3191268

Kandula, S., \& Shaman, J. (2019). Reappraising the utility of Google Flu Trends. PLoS Comput Biol, 15(8), e1007258. doi:10.1371/journal.pcbi.1007258

Kennedy, J. (2019). Populist politics and vaccine hesitancy in Western Europe: an analysis of national-level data. Eur J Public Health, 29(3), 512-516. doi:10.1093/eurpub/ckz004

Komiak, \& Benbasat. (2006). The Effects of Personalization and Familiarity on Trust and Adoption of Recommendation Agents. Mis Quarterly, 30(4). doi: $10.2307 / 25148760$

Kowatsch, T., Nißen, M., Shih, C.-H. I., Rüegger, D., Volland, D., Filler, A., . . . Büchter, D. (2017). Textbased Healthcare Chatbots Supporting Patient and Health Professional Teams: Preliminary Results of a Randomized Controlled Trial on Childhood Obesity. Paper presented at the Persuasive Embodied Agents for Behavior Change (PEACH2017) Workshop at the 17th International Conference on Intelligent Virtual Agents.

Lupton, D. (2013). The digitally engaged patient: Selfmonitoring and self-care in the digital health era. Social Theory \& Health, 11(3), 256-270. doi:10.1057/ sth. 2013.10

Lupton, D. (2016). Digital health technologies and digital data: new ways of monitoring, measuring and commodifying human bodies. Research handbook on digital transformations, 85 .

Mackert, M., Mabry-Flynn, A., Champlin, S., Donovan, E. E., \& Pounders, K. (2016). Health Literacy and Health Information Technology Adoption: The Potential for a New Digital Divide. J Med Internet Res, 18(10), e264. doi:10.2196/jmir.6349

Mayer, G. G., Villaire, M., \& Connell, J. (2005). Ten recommendations for reducing unnecessary emergency department visits. $J$ Nurs Adm, 35(10), 428-430. doi:10.1097/00005110-200510000-00003

McColl-Kennedy, J. R., Vargo, S. L., Dagger, T. S., Sweeney, J. C., \& van Kasteren, Y. (2012). Health Care Customer Value Cocreation Practice Styles. Journal of Service Research, 15(4), 370-389. doi:10.1177/ 1094670512442806

Metzger, M. J. (2006). Effects of Site, Vendor, and Consumer Characteristics on Web Site Trust and Disclosure. Communication Research, 33(3), 155-179. doi:10.1177/0093650206287076 
Metzger, M. J. (2007). Communication Privacy Management in Electronic Commerce. Journal of Computer-Mediated Communication, 12(2), 335-361. doi:10.1111/j.1083-6101.2007.00328.x

Moreira, A. C., \& Silva, P. M. (2015). The trustcommitment challenge in service quality-loyalty relationships. Int J Health Care Qual Assur, 28(3), 253266. doi:10.1108/IJHCQA-02-2014-0017

Murphy, M. (2019). Dr Google will see you now: Search giant wants to cash in on your medical queries. Retrieved from https://www.telegraph.co.uk/techno logy/2019/03/10/google-sifting-one-billion-healthquestions-day/

Murphy, S. M., \& Neven, D. (2014). Cost-effective: emergency department care coordination with a regional hospital information system. $J$ Emerg Med, 47(2), 223-231. doi:10.1016/j.jemermed.2013.11.073

NHS. (2020). Health A-Z. Retrieved from https://www.nhs.uk/conditions/

Ofir, C., \& Simonson, I. (2007). The effect of stating expectations on customer satisfaction and shopping experience. Journal of Marketing Research, 44(1), 164174. doi:DOI 10.1509/jmkr.44.1.164

Paasche-Orlow, M. K., Parker, R. M., Gazmararian, J. A., Nielsen-Bohlman, L. T., \& Rudd, R. R. (2005). The prevalence of limited health literacy. J Gen Intern Med, 20(2), 175-184. doi:10.1111/j.1525-1497.2005. 40245.x

Rawson, A., Duncan, E., \& Jones, C. (2013). The truth about customer experience. Harvard Business Review, 91(9), 90-98.

Rieffe, C., Oosterveld, P., Wijkel, D., \& Wiefferink, C. (1999). Reasons why patients bypass their GP to visit a hospital emergency department. Accident and Emergency Nursing, 7(4), 217-225. doi:10.1016/s09652302(99)80054-x

Santos, J. C., \& Matos, S. (2014). Analysing Twitter and web queries for flu trend prediction. Theor Biol Med Model, 11 Suppl 1, S6. doi:10.1186/1742-4682-11-S1S6

Soldaini, L., \& Goharian, N. (2017). Learning to rank for consumer health search: a semantic approach. Paper presented at the European conference on information retrieval.

Solomon, M. R., Surprenant, C., Czepiel, J. A., \& Gutman, E. G. (1985). A Role Theory Perspective on Dyadic Interactions: The Service Encounter. Journal of Marketing, 49(1). doi:10.2307/1251180

Sweeney, J. C., Danaher, T. S., \& McColl-Kennedy, J. R. (2015). Customer Effort in Value Cocreation Activities: Improving Quality of Life and Behavioral Intentions of Health Care Customers. Journal of Service Research, 18(3), 318-335. doi:10.1177/1094670515572128

Volkova, S., Ayton, E., Porterfield, K., \& Corley, C. D. (2017). Forecasting influenza-like illness dynamics for military populations using neural networks and social media. PLoS One, 12(12), e0188941. doi:10.1371/journal.pone.0188941

Voorhees, C. M., Fombelle, P. W., Gregoire, Y., Bone, S., Gustafsson, A., Sousa, R., \& Walkowiak, T. (2017).
Service encounters, experiences and the customer journey: Defining the field and a call to expand our lens. Journal of Business Research, 79, 269-280. doi:10.1016/j.jbusres.2017.04.014

Wang, W.-T., Cheng, S.-Y., \& Huang, L.-Y. (2013). Technology-Based Service Encounters Using SelfService Technologies in the Healthcare Industry. International Journal of Human-Computer Interaction, 29(3), 139-155. doi:10.1080/10447318.2012.695728

Wang, W. Q., \& Benbasat, I. (2007). Recommendation agents for electronic commerce: Effects of explanation facilities on trusting beliefs. Journal of Management Information Systems, 23(4), 217-246. doi:10.2753/Mis0742-122230410

Wirtz, J., Patterson, P. G., Kunz, W. H., Gruber, T., Lu, V. N., Paluch, S., \& Martins, A. (2018). Brave new world: service robots in the frontline. Journal of Service Management, 29(5), 907-931. doi:10.1108/josm-042018-0119

Xie, B. (2011). Effects of an eHealth literacy intervention for older adults. J Med Internet Res, 13(4), e90. doi:10.2196/jmir.1880

Zhang, X., Liu, S., Chen, X., Wang, L., Gao, B., \& Zhu, Q. (2018). Health information privacy concerns, antecedents, and information disclosure intention in online health communities. Information \& Management, 55(4), 482-493. doi:10.1016/j.im.2017. 11.003 